\title{
ON SOME NONDESCRIPT ANOPLURA AND MALLOPHAGA.
}

\author{
By Bruce F. Cummings.
}

(Published by permission of the Trusters of the British Museum.)

The following notes and descriptions are based on material in the collection of the British Museum :-

\author{
ANOPLURA. \\ Subfamily, Linognathinae. \\ Genus, Polyplax, Enderlein.
}

\section{Polyplax pectinata, sp. nov.}

This parasite approaches Neumann's Haematopinus (Polyplax) maniculatus, but is immediately recognised by the truncate proboscis, by the "olecranon process" of the hind pair of legs, and by the remarkable "comb" which terminates the abdomen of the $Q$. Perhaps a new genus should be made to receive it.

Linear, abdomen about four times the length of the head and thorax together. Head very broad, proboscis truncate, its lateral margins diverging to as far as the antennae, behind which the head enlarges at right angles. Post-antennal area rectangular, broad ; the occipital margin a little convex. $\Lambda$ t each posterior angle a long hair; on the under surface, at about the level of the antennae, two short bristles, one on each side. Antennae of five segments, the first being thick and stout, the second narrower and the longest, the third short, and the fourth broad with a sharp prominence at the post-axial distal corner. Adjoining the prominence a small circular sense-organ which crosses the joint and occupies part of the base of the terminal segment. The latter is longer than the third or fourth, and has several spines at the end. Thorax broader than the head and broader behind than in front. A large flattened spheroidal spiracle at each lateral margin. Sternal plate piriform. The flrst pair of legs much shorter and more slender than the rest, the coxae inserted almost longitudinally. In the third pair, the coxae are very large and broad, separated by an interval from the two anterior pairs of coxae. The third femur bears an "olecranon process" in the form of a broad scalloped plate on the post-axial margin. 'This curves downwards and the concave side of the plate shows radiating lines or grooves. The third pair of claws are broad, rounded plate-like. Abdomen very long, broader than thorax. Dorsal and ventral surfaces with transverse rows of widely spaced hairs, more than one row to each segment. Pleurae large, broad, on the lower margin deeply cleft, with two bristles in the fork of the cleft. In the $\delta$ the eighth pair of pleurae are very long, the lower margin of each extending in two long pointed processes or limbs beyond the end of the last segment; there are two long bristles in the fork of the cleft. In the $Q$ the processes of the eighth pair of pleurae are longer than the others, but they do not extend beyond the end of the abdomen. The hind margin of the terminal tergite in the $Q$ is peculiar, being drawn out into a frill or comb of long finger-shaped processes, each of which is surmounted by a. long bristle. Last segment in ot conical, truncate at 
the tip, with a small hair at each corner ; genital armature short, only just extending into the penultimate segment. Chitin everywhere shows a pronounced scaly appearance under a high power. The "scales" are imbricated and occur on the head, thorax and abdomen and may be detected on the clear chitin between the sclerites.

Length (in mm.), of, $1.40, \%, 1.85$; head, $\delta \odot, 0.15$; thorax, ơ $Q, 0.2$; abdomen, $\delta, 1 \cdot 05, Q, 1 \cdot 5$; greatest width, $\delta Q, 0.4$.

Hos't : Epimys surifer, Mill.

Malay Penixscla : Biserat, Jalor, 6. vii. 1901 (Annandale $\$$ Rolinson).

The specimens were, unfortunately, too damaged for complete description.
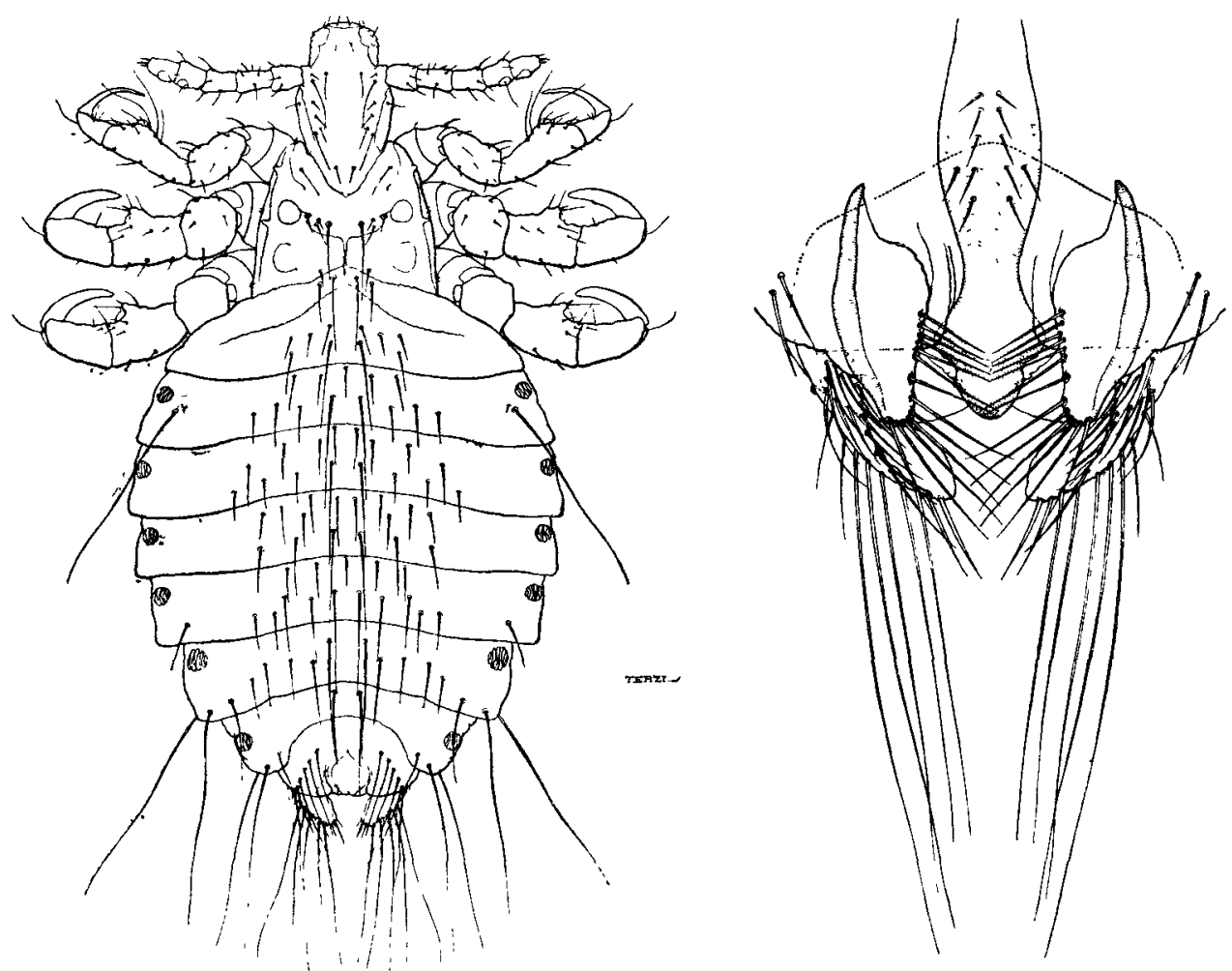

Fig. 1.-Limognathus limnotragi, Cummings, $q$, and the underside of the last segments $(q)$.

Genus Linognathus, Enderlein.

\section{Linognathus limnotragi, sp. nov.}

The new form is distinguished by the broad truncate proboscis, suggestive of I. gazella, Mjoberg; but L. limnotragi is broader, and differs in the position of the brown taches on the preantennal area of the head, the arrangement of the bristles and hairs being also quite different.

Head thick, stunted, broad and short in front, truncate at the tip of the proboscis, which bears four distinct hairs and is very rugose, with small tubercles. Two deep brown taches on each side of the preantennal area of the head, which extend a little around the anterior corners of the head, but do not meet ; on the 
ventral surface they are united by a transverse band. The head is wider behind the antennae and narrows again towards the thorax, which is V-shaped to receive it. On the upper surface, two longitudinal rows of hairs, meeting behind. A single hair in the lateral margin midway between antenna and thorax ; between the antennae, near the middle line, two small hairs ; more anteriorly, between the lateral taches, another pair of small hairs. Under surface almost bare, except for two long bristles inside the lateral margins, behind the antennae, and two more in front, closer together. Antennue long and thick, second segment a little longer than the first, and a sense-organ on the fourth and the fifth. Thorax broad and short, with two long hairs on the upper surface near the middle; spiracles large, with three small hairs on the inner side of each of them; a short bristle at each anterior corner. First pair of legs slender, with a long pointed claw ; hinder pairs larger, with broad, permanently curved, prehensile claws. Abilomen plump, broad, longer than head and thorax together. The third segment as in $I$. breviceps, Piaget, and others, with a long hair on each side, and a minute one at the base of each long one. Segments VI and VII at their lower angles carry on each side two long bristles, one dorsal and one ventral ; rows of hairs running transversely, but confined to the median areas, are found on both dorsal and ventral surfaces. In the $\delta$ the last segment on the upper surface has a large semicircular row of hairs; genital armature large and projecting on a terminal papilla. In the $Q$ the gonopods are large and thickly bristled, with a transverse row of hairs running between them. The sides of the last segment are formed into two distinct ventro-lateral, strongly chitinised pieces, each with a thick exterior margin bearing a row of long bristles. An elongate genital tache between the gonopods and extending some way beyond them behind, in shape like a slipper (crepiduloid), with two stout bristles, one on each side of it in front, and between these two short longitudinal rows of small hairs.

Length (in mm.), $\delta, 1.475$,, 2.125 ; head, $\delta, 0.3$, $\odot, 0.325$; thorax, ơ, $0 \cdot 175$. $ᄋ, 0 \cdot 2$; abdomen, $\delta, 1 \cdot 00, \bigcirc, 1 \cdot 6$; greatest width, $\delta, 0 \cdot 475, \bigcirc, 0 \cdot 8$. Host : Limnotragus gratus, Sel. (in the Zoological Gardens, Regents Park). Congo.

\section{Linognathus caviae-capensis (Pallas) (figs. 2 and 3 ).}

Pallas, in his Spicilegia Zoologica, Fasciculus II (Mammalia), 1767, describes and figures, as Pediculus caviae capensis, a parasite from the Cape Hyrax (Procavia capensis), probably identical with specimens of Anoplura from the same mammal in the collection of the British Museum. His description and his figures agree with the species described below in the sexual dimorphism, in the contour of the head, and in the long hairs on the abdomen.

Ehrenberg (Symbolae Physicae, 1828, Decas Prima, page 'f') gives the following brief diagnosis of a species, Pediculus leptocephalus, from the Syrian Hyrax ( $P$. syriacus), which he regards as differing from Pallas's insect:"Capite antennarum porrectarum articulis duobus superato gracili, oculis distinctis nullis." From this it appears probable that the species on the Syrian Hyrax is distinct.

Giebel (Insecta Epizoa, 1874, p. 47) unites the two forms under the name Haematopinus leptocephalus, though he remarks upon Ehrenberg's opinion as to their distinctness and though he had apparently nothing to go upon except the 
slender diagnoses of the original authors. Giebel misquotes Ehrenberg and then suggests that Pallas's species, according to his figure, has quite the appearance of the swine louse (H. urius). Piaget (Les Pediculines, 1880, p. 656) copies the suggestion, which is clearly an error, if for no other reason than the much smaller size of Pallas's parasite.

As the description by Pallas is inadequate, a further account is appended. Unfortunately I have no specimens from the Syrian animal for comparison, but assuming that they belong to another species, the specific name leptocephalus must be given to them, while the name cariac-capensis may be retained for Pallas's

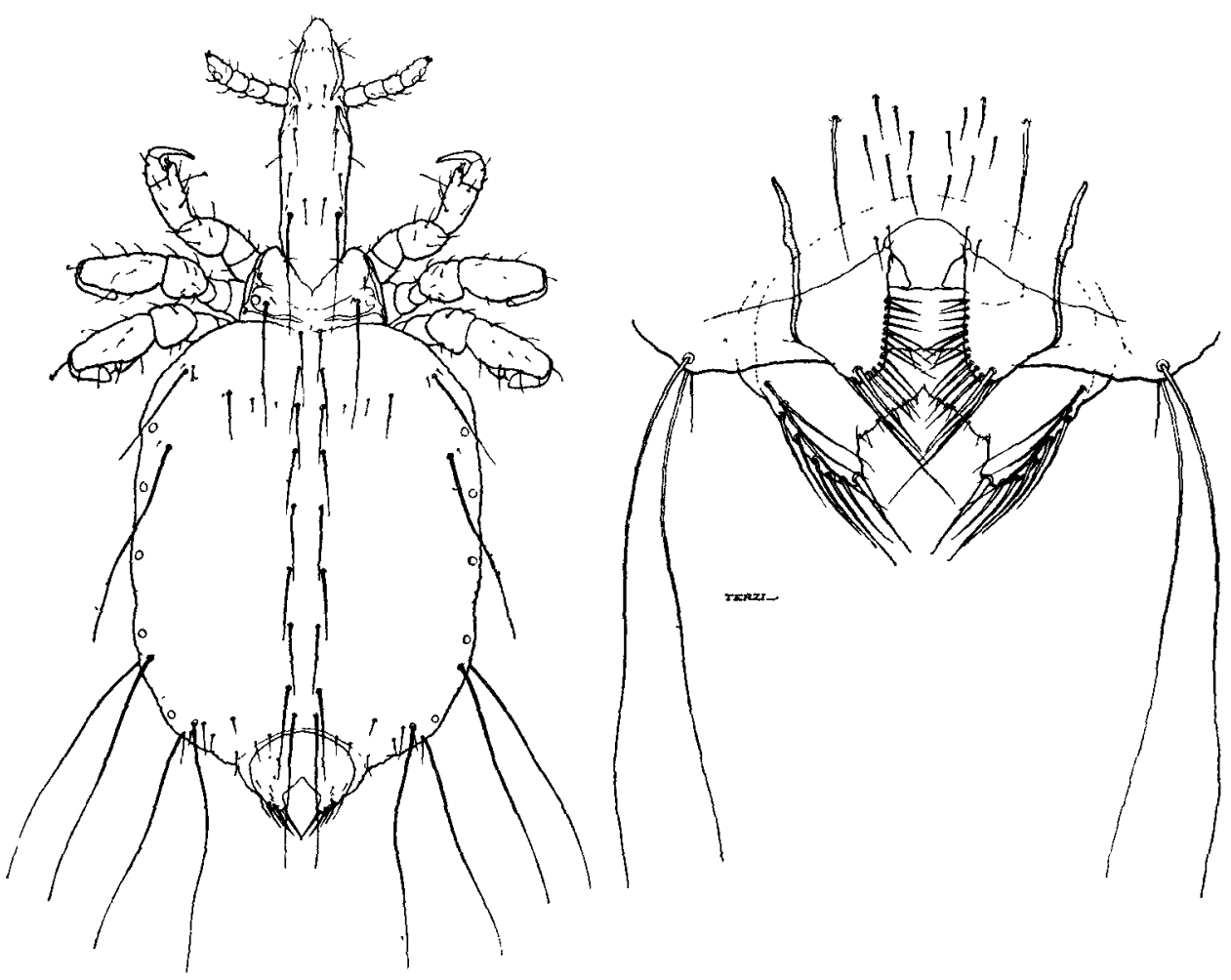

- Fig. 2.-Linognathus caviue-cupensis (Pallas), 우, and the underside of the last segments ( 9 ).

insect, although, strictly speaking, he used no name at all, but published descriptions of two animals, a Taenia and the Pediculus, under the Latin title (not name) of "Pediculus et Taenia Caviae capensis."

Head long, narrow, quadrilateral in cross-section, with four sharp edges; sucking apparatus correspondingly elongate. Preantennal area conical with 2 deep brown taches on each side, which curve in across the head towards each other at about the level of the antennae. On the dorsal surface behind the antennae, two longitudinal rows of hairs, the last one in each row being very long; two hairs on each side at the base of the antennae; two more a little further forward nearer the middle line ; still further in front, another row of only six hairs, the two outside ones being on the extreme margin; two hairs at the top of the proboscis. On the ventral surface, two hairs in front of the antennae and 
two immediately behind. Antennae of four joints, the last two segments being fused into one large swollen segment carrying two partially fused sense-organs half-way along the postaxial margin. Thorax small, short, broader than the head, anterior margin V-shaped. A long hair on the upper surface on each side near the spiracle; two more closer together on the hind margin. Abdomen oval. Two longitudinal rows of hairs running down the middle of both dorsal and ventral surfaces, two hairs above and two below on each segment; on the dorsal surface of the second segment, however, there is a transverse row of eight hairs; at the sides of the ultimate and antepenultimate segments two very long hairs; on dorsal surface of the second and third segments, a little way in from the lateral margin, a long bristle on each side. Terminal segment of $\delta$ with two

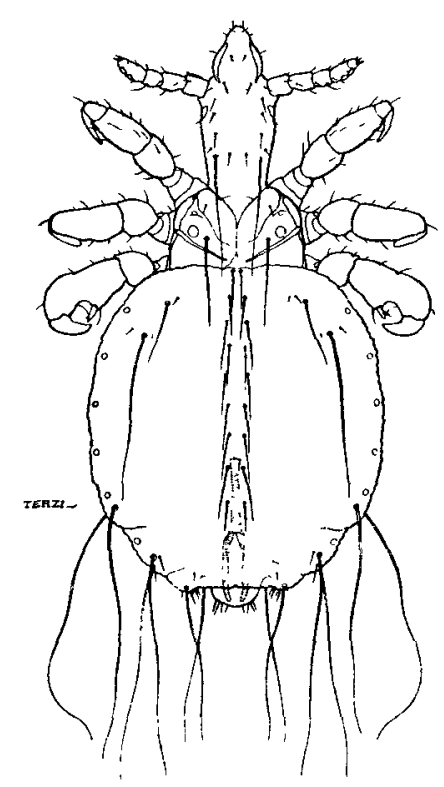

Fy. 3.-Linognathus caviae-cupensis (Pallas), of.

deep bays, one on either side of the rounded posterior margin. Gonopods long, parallel-sided, the lower inner angles rounded and produced.

$\delta$. In this sex the head is shorter, the sides converging a little towards the thorax, and the abdomen is shorter and rounder.

Length (in mm.), o $1 \cdot 25$, ㅇ 1.825; head, ơ $0 \cdot 45$, \& 0.575 ; thorax, of $ᄋ 0.25$; abdomen, of 0.55 , $Q 1.00$.

Host : the Cape Hyrax (Procavia capensis, Pallas); from the Zoological Society's Gardens, Regent's Park.

\section{MALLOPHAGA.}

Genus Trimenopon, nov.

In being a two-clawed parasite on mammals, this interesting South American insect resembles the Mallophaga of the genera Boopia, Heterodoxus and Latumcephalum. But whereas these three genera are typical of the Australian region 
and occur principally on Marsupials, the new genus is from Paraguay, and was taken on Cavia aperca. It is a robust, spiny inseet, with large, prothoracic "wings," recalling Trincton, just as Heterodoxus stands close to Menopon.

The genus is distinguished not only by the prothoracic "wings," but by the form of the genitalia and by the proportional lengths, the head and thorax together being almost as long as the abdomen.

\section{Trimenopon echinoderma, sp. nov. (fig. 4).}

Head similar to that of Menopon, broader than long. Premaxillary area semicircular ; behind the maxillae the lateral margins curve outwards in a bend and continue to diverge as far as the postero-lateral angles, which are acute;
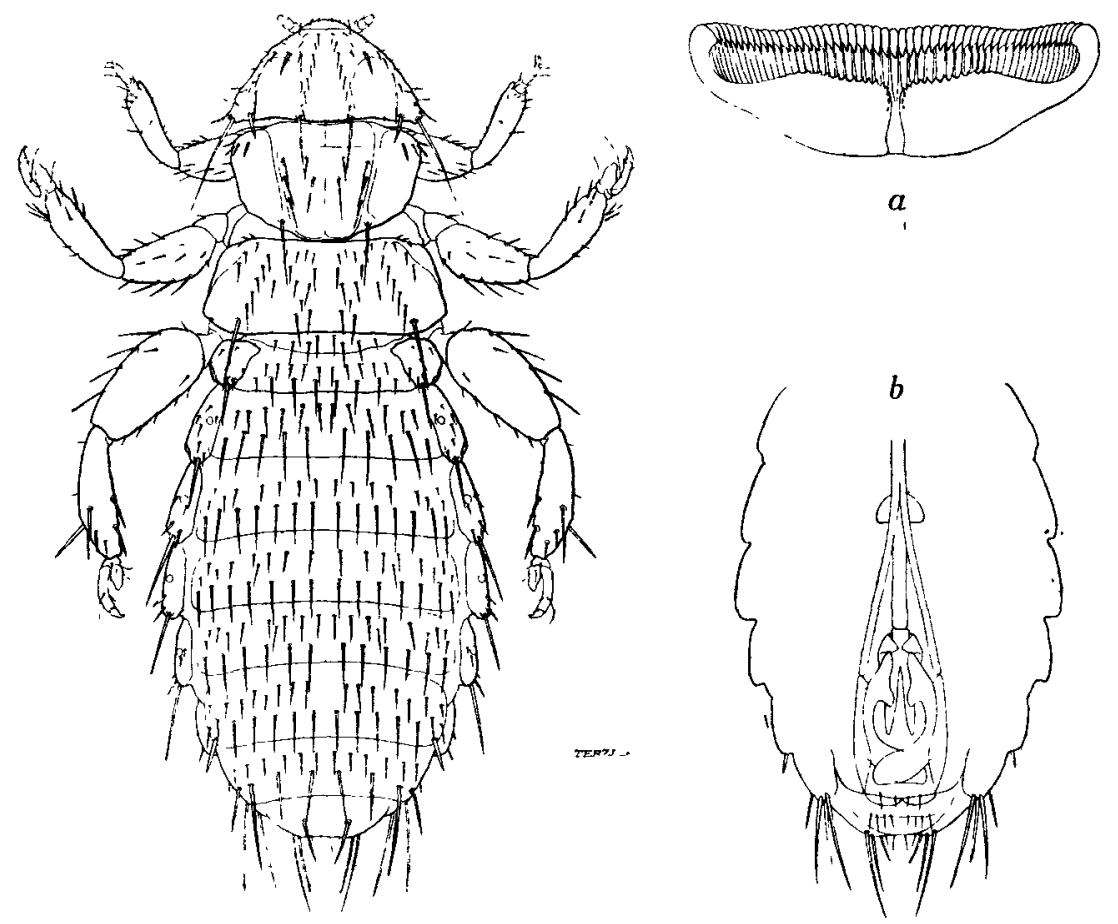

Fig. 4.-Trimenopon echinotermu, Cummings, $q ; u$, the gastric teeth ; $b$, of sexual apparatus.

occipital margin more or less straight. Two rows of hairs run longitudinally over the dorsal surface of the head; in front of each temporal fossa on the dorsal surface is a powerful spine; a transverse row of small hairs in front, at the level of the maxillary palpi, the two outer ones being on the extreme margin. Several spines along the lateral margins of the head, and on the postero-lateral corners stands a group of very stout spines, one being exceptionally long. Under surface of the head with a raised central area; at the postero-lateral angles of this a long bristle and three short ones in line in front 
of it and situated along the lateral margin of the area ; numerous other small hairs arranged symmetrically; several minute hairs around the clypeus. Maxillary palpi long, joints almost equal. Labium with two lobes on each side bearing hairs. Hypopharynx with two well-developed fringed lobes in front, a central bar of chitin running out from a broad plate behind. Antennac club-shaped, five-jointed, concealed in fossae. Thorax: pronotum with well developed lateral "wings," elegantly narrowed behind ; two longitudinal brown bands of thicker chitin divide the pronotum into three areas; the bands curve in and unite at the posterior margin ; a median groove is present; a few short sharp spines close together on the upper side of the "wings." In the middle area of the pronotum a row of four hairs, and another row of four hairs just behind; on the posterior margin of the pronotum, two long bristles with two smaller ones in front of each. The metanotum shorter, but broader, than the prothorax, being broadest on the abdomen. Spines arranged roughly in the form of an $M$; other spines arranged as indicated in the figure. Thoracic sternal areas decorated with stout spines, which on the prosternum are confined to the lateral areas. A somewhat complicated endoskeleton : two stout bars running in like clavicles towards the sternum from the "shoulders" of the pronotum; in the metathorax there is a bifid bar, one limb forming the margin of the metanotum and the other sloping down at the side to the ventral surface. Legs strong and spiny; onychium large, with the edge crenulate. Hind pair of legs stouter than the rest, with stouter spines, particularly on the tibiae. The tarsi with one or two long silky hairs. Abdomen broadest beyond the middle, ovate. Each tergite and sternite with two rows of stout hairs arranged transversely, those in the posterior row being longer than those in the anterior; tergite I with only two hairs in the first row. On the ventral surface, the outside spines of the second row of each segment very large and brown in colour. Pleural angles of the last few segments more pronounced and carrying longer bristles. Terminal segment rounded in the $\delta^{*}$, the genital armature peculiar (fig. 4b). In the $Q$, segment VIII with a semicircular plate ventrally covering the genital aperture; IX ventrally with an oblique row of bristles on each side, and behind each row an oblique band of chitin which runs backwards towards the vulva, where it bifurcates. The sexes are alike, except as regards the terminal segments.

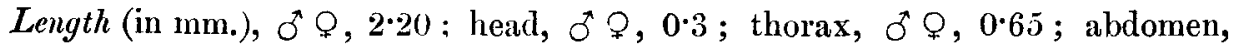
$1 \cdot 25$; greatest width, $\sigma^{\star} Q, 0 \cdot 75$.

Host : Cavia apereu, Erxleben.

Paraguay : Villa Rica, 6. xi. 1910 (F. Posner). Presented by the Hon. N. Charles Rothschild.

In specimens of both sexes, prepared with potash, a dense row of teeth and two dentate flaps (fig. $4 a$ ) are visible through the integument of the first or second abdominal segments in the position occupied by the crop. Snodgrass, in his "Anatomy of the Mallophaga" (Occas. Papers Californian Acad. of Sciences, vi, 1899 , p. 145), does not refer to the presence of gastric teeth in this order, so that perhaps it is worth while that attention be directed to them in Trimenopon. 


\section{Genus Laemobothrium, Nitzsch.}

\section{Laemobothrium opisthocomi, sp. nov. (fig. 5).}

This well characterised species from the Hoatzin, of British Guiana, is distinguished by a pronounced sexual dimorphism, the frontal margin of the head in the $\sigma$ being excavated, as in the genus Akidoproctus, while in the $P$ it is only concave. The mandibles of the $\delta$ are also longer and narrower than those of the $Q$. Abdomen of the $Q$ long, lanceolate at the end ; of the $\delta$, shorter and abruptly rounded apically. Upper surface smooth and shining, of an almost uniform brown colour, bare, except at the lateral margins.
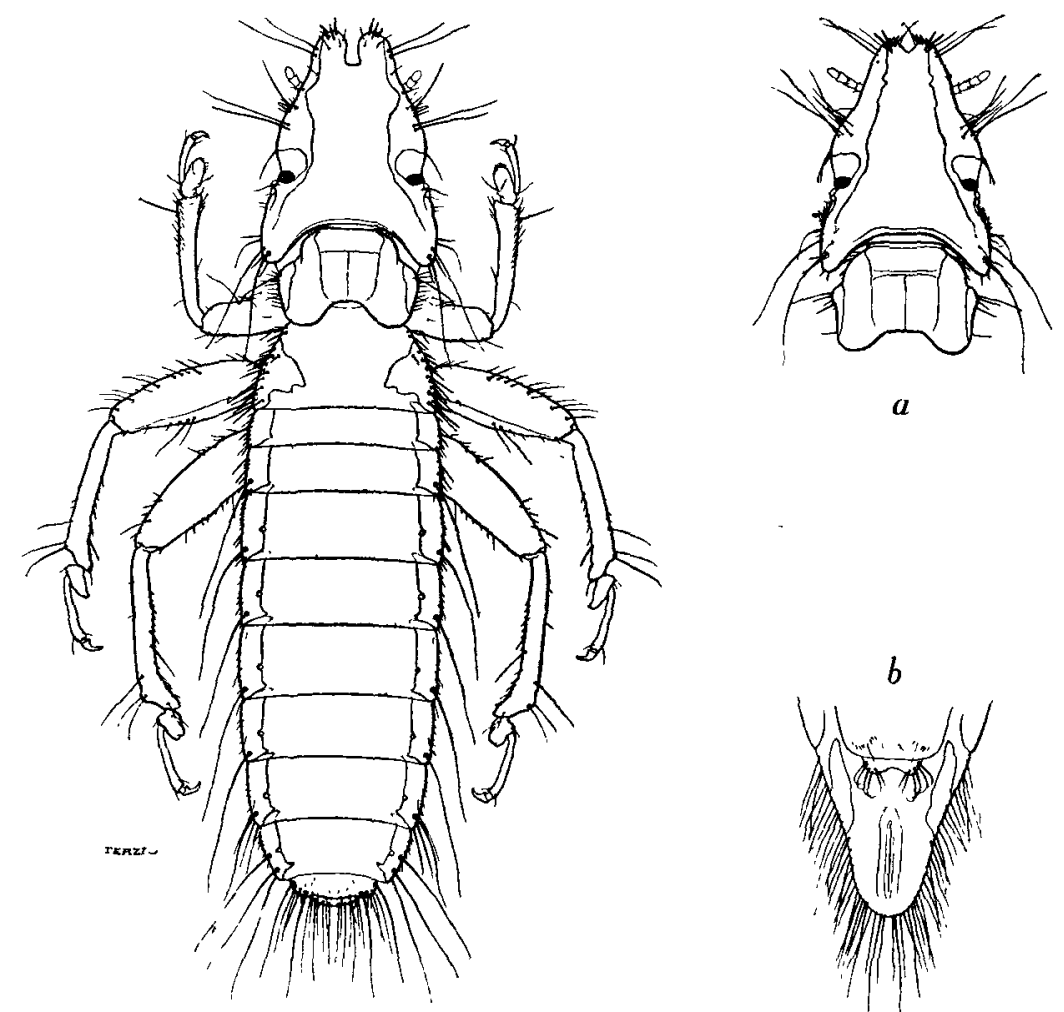

$a$

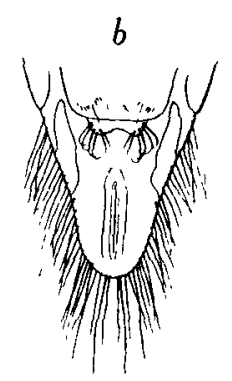

Fig. 5.-Laemobothrium opisthocome, Cummings, $\delta ; a$, head and pronotum of $o+b$, the underside of the terminal segments of .

Head elongate, very narrow in front, broadening out before the antennae; antennal fossae cireular, deep ; temples much produced behind so as to embrace the anterior narrower area of the prothorax. On each promontory of the bay on the frontal margin is a group of about five thick blunt bristles, with three or four finer hairs ; the bay bare of hairs ; on the exterior or lateral margin of each of the promontories, two long hairs and a short one a little further back; a group of long hairs on each side behind the maxillae, three of which are much longer than the rest; on the temples the usual series of rows of short hairs, ridges and 
comb-like structures present in other species of the genus; two long hairs at the posterior angles of the head. Thorax: pronotum narrow in front and rounded, enlarging abruptly at the sides, concave in the metathorax, the postero-lateral angles being large, rounded and prominent; a T-shaped impression in the upper surface. Three short hairs on each side on the anterior margin behind the head, difficult to detect without a strong lens ; about a dozen hairs on the lateral margin of the broadened posterior area of the prothorax. On the under side, an elongate sternal plate, broad in front, with a shallow bay between the two rounded anterior angles. Metathorax narrow in front and much constricted at the junction with the prothorax ; a linear median impression above, a closely set row of lateral bristles and a sternal plate shaped like a spear-head and pointing backwards. Legs long, unicolorous. The first pair of femora short and thick, the second pair twice as long, third pair still longer. The first pair of tibiae with a dense row of bristles and one long hair on the distal half of the outside margin, the tibiae of the other legs with three long hairs on the distal extremity of the outside margin. Abdomen broad and long, segments closely fitted together, so that the lateral margins are unbroken and continuous, and the smooth bare shining upper surface scarcely interrupted by the sutures. Lateral margins of thick chitin are more clearly visible from below. In the $\sigma^{*}$ the spiracle in each segment lies in a notch in the inner margin of the lateral border. The segments are of different lengths, I being the shortest, II a little longer, and each succeeding segment longer than that which precedes it. In the $\odot, I X$ is lanceolate, long and elegantly curved; in the $\sigma$ it is short, rounded and broad at the end, being received into the concavity of the posterior margin of the preceding segment. Attached to almost the whole of the posterior margin of the second sternite is a short soft flap or "flounce," $0.25 \mathrm{~mm}$. in length, grooved and furrowed longitudinally. On the lower corner of each segment a long hair, not at the angle, but just inside the margin on the dorsal surface. Upper surface of the lateral margins of each segment with a series of short hairs, one (sometimes two) of these being a little longer than the rest; on the lower side of the lateral margin of each segment, four or five small hairs; at the lower corners of segment VII a long bristle on the dorsal side, another on the ventral and several at the edge; VIII similar ; in the $Q, I X$ has a fringe of moderately long, closely spaced hairs all round the edge, and on its dorsal surface, half-way down and a little distance from the eage, four hairs in a group, one long one and the others smaller in descending ratio. Lower lip of the vulva supported by two long ill-defined slips of brown chitin, one on each side ; the upper lip partially concealed, produced into a quadrilateral flap, stretched between two stout brown rods of dense chitin; each rod with several long wiry bristles at the tip; a transverse curved slip of chitin connecting the base of each rod with the lateral margin of the segment. In the $\sigma$ the terminal tergite is short broad and elliptical, with several long hairs at the sides and two very long hairs, one on each side of the posterior margin; across its breadth a series of minute bristles; the whole area of the tergite divided up by a median and a transverse pale line into four taches, the two anterior ones being the shortest; just within the terminal aperture is a somewhat bilobed lappet, with four hairs on each lateral lobe. Terminal sternite longer than and overlapping the tergite, a median longitudinal line dividing it into two areas. 


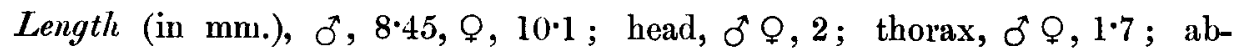
domen, $\delta, 4 \cdot 75, Q, 6 \cdot 4$

Host : the Hoatzin (Opisthocomus cristatus).

British Guiana (presented by the Hon. N. C. Rothschild).

Lacmobothrium is the parasite par excellence of the birds of prey, though it also occurs in Gallinula, Fulica and Psophia, and has been reported from the ostrich.

\section{Dochophorus on Bombus.}

\section{Miscellaneous Notes.}

B. Wanach (Ent. Rund. 1910) records the transport of a Philopterus by Ornithomyia avicularia, L., and Mitzmain (Philippine Agric. Rev., v, 12th December 1912) reports the Anopluran, Haematopinus tuberculatus (Nitzsch), as attaching itself in its earlier stages to the legs of Lyperosia. It is perhaps of interest to record here in this connexion that the British Museum collection contains a fragmentary specimen of an unidentified species of Dochophorns taken from Bombus hyperboreus, from Hayes Sound, 79 N. Lat.

Heterodoxus longitarsus (Piaget) $(=H$. mucropus, Le Souëf and Bullen).

In the "Victorian Naturalist" for February 1902, p. 159, Messis. S. A. Le Souëf and H. Bullen give a summary description and a rough figure of an Amblyceran which they name Heterodoxus mucropus, found on the kangaroo. Examples of this parasite which Mr. Le Souëf presented to the British Museum agree almost in toto with Piaget's species Menopon longitarsus ("Yues Pédiculines," p. 504), from Helmaturus giganteus. Prof. L. G. Neumann (Archives de Parasitologie, xv, 1912, p. 353) records $M$. longitarsus from a kangaroo in the Jardin des Plantes. I have been unable to compare $H$. mucropus with the type of M. longitarsus but Piaget's full description and figure and Neumann's figure of the head are sufficient to put the matter beyond doubt. 'The Australian authors comment on its likeness to the genus Menopon, but in consequence of the fact that its host is a marsupial mammal and not a bird (as in almost all other MENOPONIDAE) they decided to found the new genus Heterododus for it; which should perhaps be allowed to stand, especially as I find the hypopharynx differs markedly in structure from that of other MENOPONIDAE so far examined. Heterodoxus longitarsus (Piaget 1880) from a mammal is mentioned by Piaget with Colpocephalum truncatum (on Phascolomys fossor), and Menopon extraneum (on Cavia cobaya), also from mammals. The British Museum collection contains specimens of $\boldsymbol{H}$. longitarsus from the Wallaby (N. Queensland), from Corone australis (Victoria), from the $\operatorname{dog}$ (Borneo), and the jackal (Somaliland), so that this species is able to exist on a variety of hosts, in many parts of the world.

\section{Hybophthirus notophallus, Neumann.}

This peculiar parasite from the equally peculiar Cape Ant-eater, Orycteropus afer, was described in 1909 both by Enderlein and by Neumann. The latter's description under the name Haematopinus notophallus was the first to be published, in the Jahrbücher des Nassauischen Vereins für Naturkunde in Wiesbaden; while Enderlein's description under the new genus Hylophthirus appeared, 
according to a note received from Gustar Fischer, on 29th December 1909, in the Denkschriften der Medizinisch-Naturwissenschaftlichen Gesellschaft, when the Jahrbiicher had been out for more than a month.

\section{Haematopinus tuberculatus (Nitzsch).}

There are several specimens of this species in the collection of the British Museum from the camel, which is further evidence in support of a suggestion thrown out by Prof. L. G. Neumann that the " Pidocchio del Cammello," figured by Redi (1668, Esperienze intorno alla generazione degl' insetti) and named Pediculus cameli by Linnaeus, is $H$. tuberculatus. I have also examined several specimens from the Chinese water buffalo. 